\title{
Mafa expression enhances glucose-responsive insulin secretion in neonatal rat beta cells
}

\author{
C. Aguayo-Mazzucato • A. Koh • I. El Khattabi • \\ W.-C. Li • E. Toschi • A. Jermendy • K. Juhl • K. Mao • \\ G. C. Weir • A. Sharma $\cdot$ S. Bonner-Weir
}

Received: 16 August 2010 / Accepted: 25 November 2010/Published online: 29 December 2010

(C) Springer-Verlag 2010

\begin{abstract}
Aim/hypothesis Neonatal beta cells lack glucose-stimulated insulin secretion and are thus functionally immature. We hypothesised that this lack of glucose responsiveness results from a generalised low expression of genes characteristic of mature functional beta cells. Important glucose-responsive transcription factors, Mafa and $P d x 1$, regulate genes involved in insulin synthesis and secretion, and have been implicated in late beta cell development. The aim of this study was to assess whether Mafa and/or $P d x 1$ regulates the postnatal functional maturation of beta cells. Methods By quantitative PCR we evaluated expression of these and other beta cell genes over the first month compared with adult. After infection with adenovirus expressing $M A F A, P d x 1$ or green fluorescent protein (Gfp), P2 rat islets were evaluated by RT-PCR and insulin secretion with static incubation and reverse haemolytic plaque assay (RHPA).

Results At P2 most beta cell genes were expressed at about $10 \%$ of adult, but by P7 Pdxl and Neurod 1 no longer differ from adult; by contrast, Mafa expression remained significantly lower than adult through P21. Overexpression of $P d x 1$ increased Mafa, Neurod1, glucokinase (Gck) mRNA and insulin content but failed to enhance glucose respon-
\end{abstract}

Electronic supplementary material The online version of this article (doi:10.1007/s00125-010-2026-z) contains supplementary material, which is available to authorised users.

C. Aguayo-Mazzucato · A. Koh • I. El Khattabi • W.-C. Li •

E. Toschi • A. Jermendy $\cdot$ K. Juhl $\cdot$ K. Mao $\cdot$ G. C. Weir •

A. Sharma $(\varangle) \cdot$ S. Bonner-Weir $(\square)$

Section of Islet Cell and Regenerative Biology,

Joslin Diabetes Center, Harvard Medical School,

One Joslin Place,

Boston, MA 02215, USA

e-mail: susan.bonner-weir@joslin.harvard.edu

e-mail: arun.sharma@joslin.harvard.edu siveness. Similar overexpression of MAFA resulted in increased Neurod1, Nkx6-1, Gck and Glp1r mRNAs and no change in insulin content but, importantly, acquisition of glucose-responsive insulin secretion. Both the percentage of secreting beta cells and the amount of insulin secreted per beta cell increased, approaching that of adult beta cells.

Conclusions/interpretation In the process of functional maturation acquiring glucose-responsive insulin secretion, neonatal beta cells undergo a coordinated gene expression programme in which Mafa plays a crucial role.

Keywords Beta cell development · Insulin secretion . MAFA $\cdot$ Maturation
Abbreviations
GFP Green fluorescent protein
GLP1R Glucagon-like peptide 1 receptor
GCK Glucokinase
GLP1R Glucagon-like peptide 1 receptor
MAFA v-Maf musculoaponeurotic fibrosarcoma oncogene homologue A (avian)
MAFB v-Maf musculoaponeurotic fibrosarcoma oncogene homologue B (avian)
PCSK1 Prohormone convertase 1/3
PDX1 Pancreatic and duodenal homeobox 1
RHPA Reverse haemolytic plaque assay
TBST Tris-buffered saline containing $0.2 \%$ Tween 20
UTR Untranslated

\section{Introduction}

Currently insulin-positive cells produced in vitro lack glucoseresponsive insulin secretion and so must be considered 
functionally immature $[1,2]$. Similarly, fetal and neonatal beta cells lack glucose responsiveness [3-5], providing a model to study the postnatal acquisition of glucose responsiveness. The molecular basis of this functional immaturity has been suggested as impaired function of calcium channels [6], of stimulus-secretion coupling [7, 8], or of the mitochondrial NADH shuttles [9]. However, based on gene profiling on laser-capture microdissected beta-cell-enriched cores of islets from neonatal (P1) and adult rats, we hypothesised that the lack of glucose responsiveness in neonatal islets was probably due to a generalised immaturity of the specialised metabolism of pancreatic beta cells. A number of genes, including key metabolic genes, had very low expression in neonatal beta cells, but there were few differences in genes for exocytotic machinery [10].

With many genes differentially expressed in the neonatal beta cell, a possible role of differential expression of key beta-cell-enriched transcription factors must be considered. $P d x 1$ and Mafa are most likely to be involved in the maturation process, because their expression is turned on after that of insulin during development [11]. Target genes of both $P d x 1$ [12] and Mafa [13] have been reported, with many exocytotic genes regulated by $P d x l$, and genes of insulin synthesis and secretion regulated by Mafa. $P d x l$ is crucial in pancreas formation [14, 15] and beta cell differentiation [16-18]. A role for Mafa in maturation is supported by: (1) several of its putative target genes (insulin 2, prohormone convertase 1/3 (Pcskl) and glucagon-like peptide 1 receptor (Glplr) [13]) have reduced expression in neonatal beta cells [10]; (2) the switch from $\mathrm{MAFB}^{+}$ $\mathrm{MAFA}^{-} \mathrm{INS}^{+}$to $\mathrm{MAFB}^{-} \mathrm{MAFA}^{+} \mathrm{INS}^{+}$is a late stage event in beta cell differentiation [11] (INS, insulin; MAFA, v-Maf musculoaponeurotic fibrosarcoma oncogene homologue A [avian]; MAFB, v-Maf musculoaponeurotic fibrosarcoma oncogene homologue B [avian]); and (3) Mafa-deficient mice appearing normal at birth but postnatally developing impaired secretagogue-stimulated insulin secretion and glucose intolerance [19]. In addition, insulin-expressing $\mathrm{MAFB}^{+}$cells derived from human embryonic stem cells lacked glucose-stimulated insulin secretion in vitro [1, 20] but acquired both glucose responsiveness and MAFA production after transplantation into mice [2].

To assess whether maturation of neonatal beta cells into glucose-responsive insulin secreting cells is regulated by $P d x 1$ and/or Mafa, we characterised their expression and that of other key beta cell genes during the first 4 weeks of postnatal life. We found expression of Mafa, $P d x l$ and many other beta cell genes expressed at only about $10 \%$ of adult levels in the first postnatal week, with increasing but differing patterns until P28. We hypothesised that enhancing the expression levels of these factors in neonatal beta cells could drive the acquisition of glucose-responsive insulin secretion. We showed that adenoviral-mediated overexpression of either MAFA or Pdx1 in $\mathrm{P} 2$ islet cells significantly enhanced their maturation. However, overexpressed $P d x 1$ failed to increase glucose responsiveness, whereas MAFA increased glucose responsiveness with increased percentage of secreting cells and increased insulin secretion by individual cells.

\section{Methods}

Animals Female Sprague-Dawley rats with various aged litters (P0 as day of birth) (Taconic Farms, Germantown, NY, USA) were kept under conventional conditions with free access to water and food. Islets were isolated from P2, P7, P9, P11, P13, P15, P21 and P28 and adult 10-week-old rats by collagenase digestion [21] and after an overnight culture in RPMI 1640 (11 mmol/1 glucose, 10\% FBS) handpicked to ensure high purity. For each P2 or P7 sample, islets from 10 animals were pooled; for P9-P28, islets from two to three animals; for adults, islets from one animal. For each age, there were three to six samples. For immunostaining, pancreases were excised and either fixed for $2 \mathrm{~h}$ in $4 \%$ paraformaldehyde for paraffin embedding or embedded in optimal cutting tissue compound (OCT) medium (Tissue Tek, Torrance, CA, USA) and processed for frozen blocks. All animal procedures were approved by the Joslin Institutional Animal Care and Use Committee.

Adenovirus infection Human MAFA coding sequence (cds) was used to generate Adeno-CMV-hMAFA-IRES-green fluorescent protein ( $G f p$ ) (Ad-MAFA) based on pShuttle vector (Stratagene, La Jolla, CA, USA); adenovirus containing the coding sequence for $P d x 1$ (Ad- $P d x l$ ) was a kind gift from D. Melton (Howard Hughes Medical Institute, Harvard University, Cambridge, MA, USA) [22]; Adeno-CMV-IRES-Gfp (Ad-Gfp) was used as control. Neonatal and adult islets were partially dispersed, plated on gelatin-treated dishes, and infected overnight with adenovirus in RPMI 1640 (11 mmol/l glucose, 10\% FBS), washed and cultured for 3-5 days in RPMI ( $20 \mathrm{mmol} / \mathrm{lglucose}$, $10 \%$ FBS). The high glucose concentration permits the strongest Mafa and Pdxl transcriptional effects. After $72 \mathrm{~h}$, samples were tested for secretion, extracted for RNA or fixed for immunostaining.

Quantitative RT-PCR Total RNA was isolated using PicoRNA extraction kit (Arcturus, Carlsbad, CA, USA) and reverse transcribed to obtain cDNA (SuperScript reverse transcriptase; Invitrogen, Carlsbad, CA, USA). Quantitative RT-PCR with SYBR green detection was performed using specific primers (Electronic supplementary material $[\mathrm{ESM}]$ Table 1). Samples were normalised to a 
control gene (S25), and the comparative threshold cycle method used to calculate gene expression levels. Adenoviral-hMAFA mRNA was determined by comparison of two different sets of primers: one recognising the cds of both endogenous (rat) and adenoinfected (human) $M A F A$, and the other recognising the $3^{\prime}$ untranslated (UTR) sequence of Mafa only present in the endogenous transcript.

Immunostaining Paraffin sections or formalin-fixed cells in dishes were incubated overnight with rabbit anti-MAFA (1:500 [11]); rabbit anti-glucagon-like peptide 1 receptor (GLP1R) (1:1,000; a kind gift from J. Habener and T. Kieffer, Massachusetts General Hospital, Boston, MA, USA [23]) or rabbit anti-prohormone convertase type 1 (PCSK1) (1:500; Abcam, Cambridge, MA, USA) at $4^{\circ} \mathrm{C}$ followed by a biotin-streptavidin system conjugated to Alexa fluor 488 (1:200) for GLP1R and PCSK1 and to VIP (Vector, Burlingame, CA, USA) for MAFA. In addition, sections were incubated with guinea pig anti-insulin (1:200; Linco, Billerica, MA, USA) for $2 \mathrm{~h}$ at room temperature, followed by FITC or Texas Red anti-guinea pig $\operatorname{IgG}(1: 200$; Jackson ImmunoResearch Laboratories, Westgrove, PA, USA). For quantification of nuclear MAFA, frozen sections were incubated with rabbit anti-MAFA antibody $(1: 1,500$; Bethyl Laboratories, Montgomery, TX, USA), followed by biotinylated anti-rabbit IgG antibody (Jackson ImmunoResearch Laboratories) and streptavidin-conjugated Alexa fluor 488 antibody (Invitrogen). These sections were also immunostained for insulin; DAPI was used for nuclear staining. Images for each antigen were taken in confocal mode on a Zeiss LSM 410 or 710 microscope at the same settings and handled similarly in Adobe Photoshop across all images; at least three animals per age were examined.

Insulin-positive cells were identified and counted as high, low or not detected for MAFA or pancreatic and duodenal homeobox 1 (PDX1) nuclear staining on images based on the relative intensity of the fluorescent signal. Between 20 and 82 different islets were sampled for each age; values from individual animals (three to five) were averaged for each age.

Insulin secretion in vitro Insulin secretion was measured in static conditions after 5 days culture in P2 Ad-Gfp, P2 Ad$M A F A$, P2 Ad-Pdx1, adult Ad-Gfp, and adult and P2 untreated islets by sequential incubation in $2.6 \mathrm{mmol} / \mathrm{l}$ and $16.8 \mathrm{mmol} / \mathrm{l}$ glucose in KRB (16 mmol/1 HEPES and $0.1 \%$ BSA, pH 7.4) as previously described [24]. Supernatant fractions and cells were frozen until assayed with Insulin Rat (EIA) kit (ALPCO, Salem, NH, USA).

Alternatively, we measured insulin secretion of single beta cells using the reverse haemolytic plaque assay (RHPA) as previously described [25]. After 5 days culture, cells were completely dispersed and mixed with $18 \%$ suspension of protein A-coated sheep erythrocytes and introduced into a poly-L-lysine-coated glass Cunningham chamber. They were challenged for $2 \mathrm{~h}$ with 2.6 or $16.8 \mathrm{mmol} / 1$ glucose in KRB in the presence of guinea pig anti-insulin antiserum (1:40, generated in our laboratory) and after $30 \mathrm{~min}$ incubation with guinea pig complement (1:40; Calbiochem, San Diego, CA, USA) were fixed with $2.5 \%$ glutaraldehyde. Secreted insulin was revealed as haemolytic plaques around secreting cells. A secretion index (average plaque area multiplied by the percentage of plaque-forming cells) indicated the overall secretory activity of beta cells under a given condition.

Western blot analysis Total protein extracts of sonicated islets $(20 \mu \mathrm{g})$ were boiled, resolved on $10 \%$ SDS-PAGE, transferred to polyvinylidene fluoride (PVDF) membranes and probed with either MAFA $(1: 2,000$ [11]) or PDX-1 (1:1,000; Upstate, Lake Placid, NY, USA) antibodies. Actin was used as a loading control. Primary antibodies were diluted in Tris-buffered saline containing $0.2 \%$ Tween 20 (TBST). Membranes were washed in TBST, incubated with either anti-rabbit or anti-mouse secondary antibodies conjugated to horseradish peroxidase and processed using either chemiluminescence SuperSignal West Dura or West Dura Femto reagent (Pierce, Rockford, IL, USA).

Data analysis Data are shown as mean \pm SEM. For statistical analysis, unpaired Student's $t$ test was used. A $p$ value $<0.05$ was considered statistically significant.

\section{Results}

Expression of beta cell transcription factors during the postnatal period We had previously found by microarray analysis the reduced expression of many key beta cell genes in neonatal beta cells, suggesting that regulated expression of transcription factors may drive beta cell maturation. To examine the expression of these factors, quantitative RTPCR was performed on neonatal islets isolated over the first postnatal month. Key beta cell transcription factors (Fig. 1a) had very low (3-12\%) expression at P2, with sharp increases between P7 and P9 (Table 1). By P7 both $P d x 1$ and Neurod 1 mRNA levels no longer differed from adult levels and from P9 to P13 were transiently higher than adult $(P d x l$ was increased in all samples but did not reach significance). $N k x 6-1$ mRNA was expressed at levels lower than adult only through P7. Unexpectedly Mafb mRNA, which is expressed in alpha cells and immature beta cells, did not differ from adult even at P2 and rose to 15 -fold higher than adult by $\mathrm{P} 9$, remaining significantly elevated even at P28 (ESM Fig. 1). By contrast, Mafa expression 
a

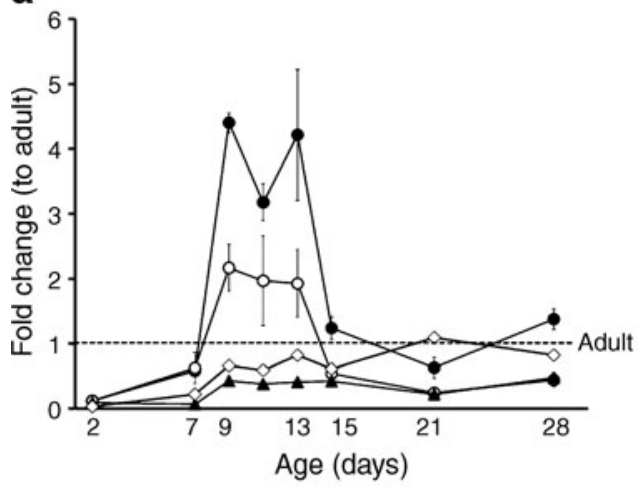

C

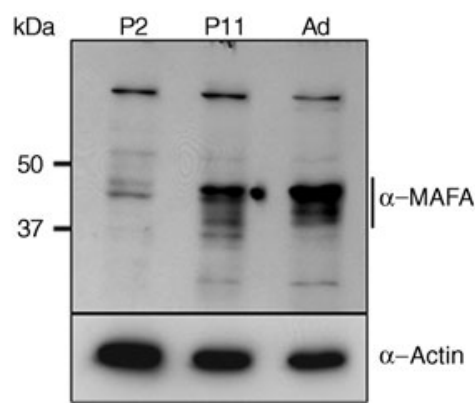

Fig. 1 Expression pattern of beta cell transcription factors during the first postnatal month. a Beta cell transcription factors Neurodl (black circle), $P d x 1$ (white circle), Mafa (black triangle), Nkx6-1 (white diamond); (b) other key genes: Glplr (black diamond), Pc (white square), Pcsk1 (white triangle), insulin (black circle), Glut2 (black square) and Gck (white circle) mRNA show different patterns of expression over the neonatal period as measured by quantitative RTPCR. Data expressed as fold change with respect to adult using S25 as internal control gene. Mean \pm SEM, $n=4-6$ isolated samples per age, each pooled from three to ten animals. The same samples were analysed in Fig. 1a, b and ESM Fig. 1. Quantification of the beta cell

increased from $7 \%$ at $\mathrm{P} 7$ to $43 \%$ of adult at $\mathrm{P} 9$ but remained significantly lower than adult until P28.

We further explored the role of PdxI and Mafa in functional maturation because both are major regulators of insulin gene expression. Mafa expression during the neonatal period seemed independent of $P d x l$ expression. Interestingly, the pattern of insulin mRNA mirrored b

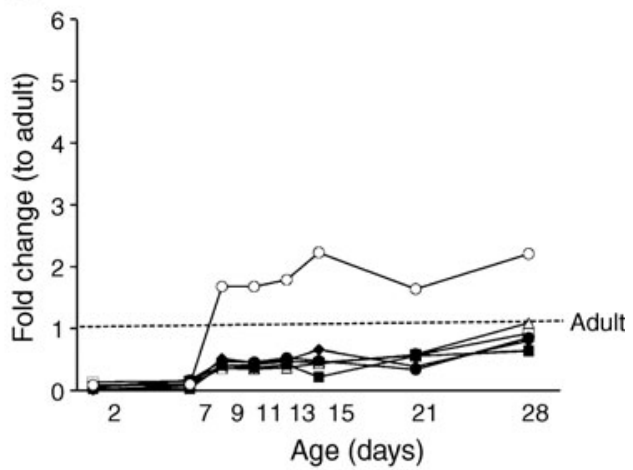

d

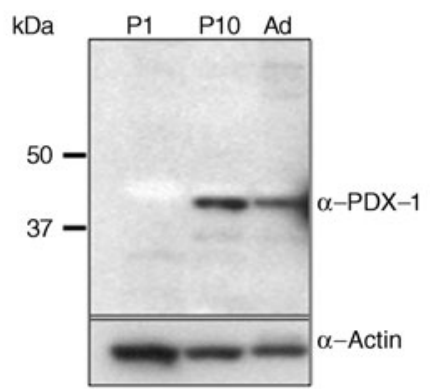

proportion showed isolated neonatal islets did not significantly differ from adult in $\%$ beta cell [10]. Only P11 had significantly lower \% beta cell than adult; P11 also had significantly lower than P1-2 but not P21. Thus the changes in gene expression are likely to be due to changes in phenotype rather than proportion of beta cells. By western blot, MAFA protein (c) and PDX1 (d) protein are low at birth (P2). MAFA increases at P11 but is still low compared with adult. PDX1 increased at P11 and decreased in adult islets in a pattern similar to that of mRNA levels at the same ages. Representative gels of three independent samples. Ad, adult

more closely that of Mafa than either Pdxl or Neurodl (Fig. 1a, b).

MAFA protein levels showed age-dependent increases. In western blots, MAFA protein (Fig. 1c) reflected the RNA levels with very low levels in P2 islets and increases in P11. PDX1 protein, by western blot (Fig. 1d) and immunohistochemistry (Fig. 2a), showed comparable levels at P11 and

Table 1 Time course expression of islet transcription factors

\begin{tabular}{|c|c|c|c|c|c|c|c|c|}
\hline \multirow[t]{2}{*}{ Transcription factor } & \multicolumn{8}{|l|}{ Age (days) } \\
\hline & 2 & 7 & 9 & 11 & 13 & 15 & 21 & 28 \\
\hline Mafa & $0.09 \pm 0.06^{*}$ & $0.07 \pm 0.03^{*}$ & $0.43 \pm 0.02 *$ & $0.38 \pm 0.05^{*}$ & $0.41 \pm 0.02 *$ & $0.42 \pm 0.05^{*}$ & $0.22 \pm 0.08^{*}$ & $0.48 \pm 0.07$ \\
\hline$P d x 1$ & $0.12 \pm 0.06^{*}$ & $0.62 \pm 0.24$ & $2.17 \pm 0.36$ & $1.97 \pm 0.69$ & $1.93 \pm 0.52$ & $0.54 \pm 0.14$ & $0.24 \pm 0.07 *$ & $0.44 \pm 0.1$ \\
\hline Neurodl & $0.12 \pm 0.09^{*}$ & $0.58 \pm 0.08$ & $4.4 \pm 0.15^{*}$ & $3.18 \pm 0.29 *$ & $4.22 \pm 1.01^{*}$ & $1.24 \pm 0.18$ & $0.63 \pm 0.16$ & $1.38 \pm 0.16$ \\
\hline$N k x 6-1$ & $0.03 \pm 0.02 *$ & $0.22 \pm 0.09 *$ & $0.66 \pm 0.02$ & $0.59 \pm 0.04$ & $0.82 \pm 0.13$ & $0.61 \pm 0.18$ & $1.09 \pm 0.15$ & $0.82 \pm 0.08$ \\
\hline$M a f b$ & $0.62 \pm 0.32$ & $3.25 \pm 0.51 *$ & $15.51 \pm 3.95^{*}$ & $14.24 \pm 2.08^{*}$ & $19.3 \pm 1.91^{*}$ & $4.96 \pm 0.94 *$ & $2.78 \pm 0.91 *$ & $4.49 \pm 0.8^{*}$ \\
\hline
\end{tabular}

Mean \pm SEM; $* p<0.05$

Values are fold change with respect to adult islets 
a

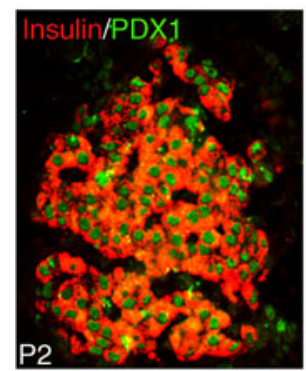

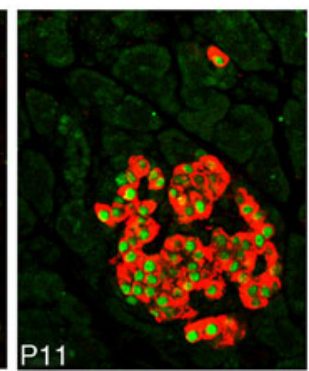

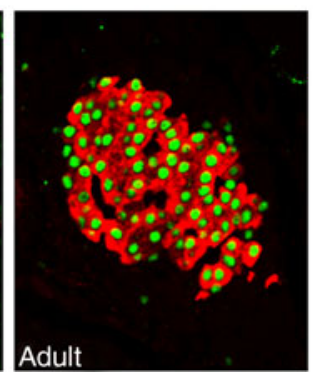

b

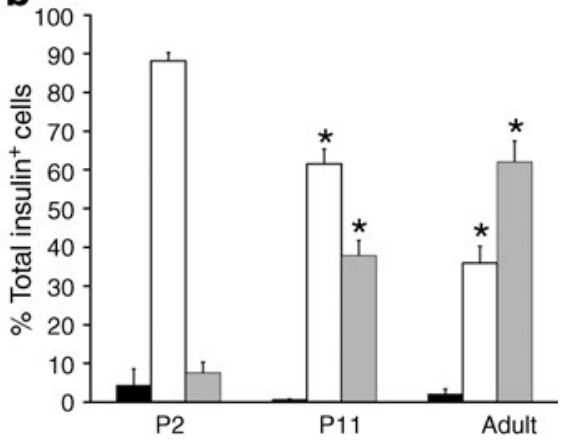

Fig. 2 PDX1 protein levels change in intensity during the postnatal period. a By immunostaining, PDX1 protein (green) in insulin ${ }^{+}$cells (red) is low at birth (P2) and increases progressively until most beta cells are PDX $1^{\text {high }}$ in adults. b Quantification of nuclear PDX1 levels shows that already at P2 almost all insulin positive cells produced detectable PDX1 and the intensity of staining increases with age. Undetectable PDX1 (black bars), PDX $1^{\text {low }}$ (white bars), PDX $1^{\text {high }}$ (grey bars). Total insulin ${ }^{+}$cells counted: P2, 463; P11, 2,286; adult, 1,092 (five pancreases per age). Mean \pm SEM. ${ }^{*} p<0.05$ with respect to previous age adult, whereas mRNA levels tended to be higher at P11 (Fig. 1a). The higher mRNA than protein levels may reflect the presence of cytoplasmic PDX1 at P2 and P11 and posttranscriptional regulation of PDX1. At P2 about $90 \%$ of beta cells had PDX $1^{\text {low }}$ staining (Fig. $2 \mathrm{a}, \mathrm{b}$ ); PDX $1^{\text {high }}$ beta cells increased from $10 \%$ at $\mathrm{P} 2$, to $40 \%$ at $\mathrm{P} 11$ and $60 \%$ in adult islets. Similarly MAFA protein was produced at low levels at $\mathrm{P} 0$; by $36 \mathrm{~h}$ of age most of the protein in the majority of cells was cytoplasmic and by P15 had become increasingly nuclear (Fig. 3a). It was possible to evaluate subcellular MAFA localisation with insulin counterstaining, which clearly demarcates cytoplasmic vs nuclear compartments. At P2 (Fig. 3b, ESM Fig. 2), 68\% of beta cells had no detectable nuclear MAFA and by P11 $60 \%$ had low levels of nuclear MAFA protein, while in the adult $95 \%$ had detectable nuclear MAFA staining (64\% MAFA $^{\text {high }}$ and $31 \%$ MAFA $^{\text {low }}$ ). At the early ages both nuclear and cytoplasmic MAFA were seen in different islets within the same pancreas (ESM Fig. 3); it was the proportion of cells expressing nuclear MAFA that changed with age. At P1 nuclear MAFA staining was seen in 26\% MAFA-positive cells but at $\mathrm{P} 10$ in $76 \%$. Murine beta cells also produced cytoplasmic MAFA at P0 and P2 (ESM Fig. 4), but by P7 their nuclear MAFA level was greater than seen in rats at similar age. These data show that by P11, $P d x 1$ mRNA and nuclear protein levels approached that of adult, whereas Mafa mRNA and nuclear protein remained significantly lower than adults.

Putative Mafa targets (insulin, Glut2, Gck, Glp1r and Pcsk1) had an expression pattern similar to that of Mafa, with very low expression at $\mathrm{P} 2$, and significant increases from P7 to P9; however, unlike Mafa, these genes reached adult mRNA levels by P28 (Fig. 1b). Immunostained neonatal pancreas showed corresponding increases in insulin, glucagon-like peptide 1 receptor (GLP1R) and PCSK1 proteins with age (Fig. 4). As the tissues and sections were handled identically and all images were taken in parallel at the same settings, signal intensity differences reflect differences in protein production. Interestingly, Gck mRNA increased from $10 \%$ adult level at $\mathrm{P} 7$ to $168 \%$ at $\mathrm{P} 9$, a
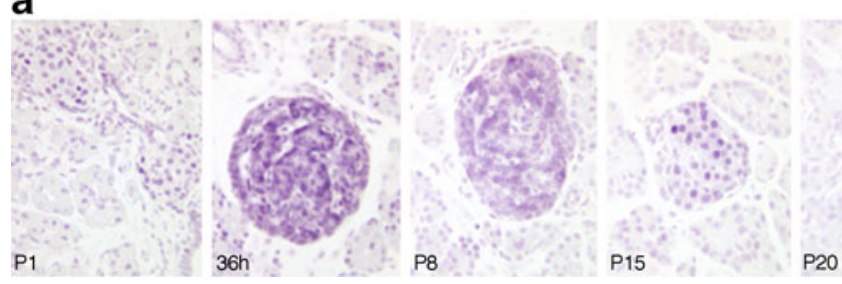

Fig. 3 MAFA protein levels change in intensity and localisation during the postnatal period. a By immunostaining, MAFA protein is low at birth (P0) and mainly cytoplasmic at $36 \mathrm{~h}$ after birth. By P15 it has increased and has more nuclear localisation. In adult islets MAFA protein is clearly nuclear. b Quantification of nuclear MAFA levels from immunofluorescent images (see ESM Fig. 2) showed at P2 only

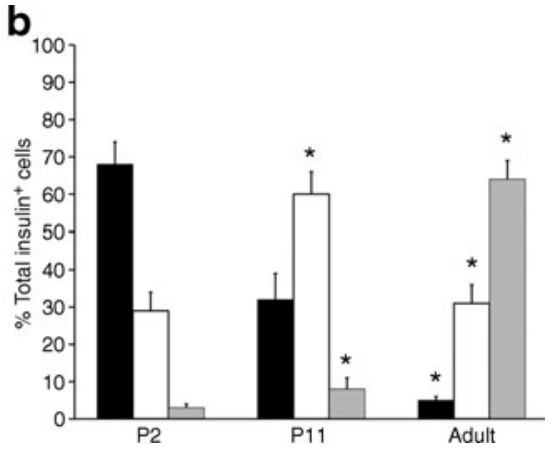

$30 \%$ MAFA $^{\text {low }}$ insulin positive cells (white bar) and less than $5 \%$ MAFA $^{\text {high }}$ (grey bar) while the rest had undetectable MAFA levels (black bar). In the adult $95 \%$ of beta cells were $\mathrm{MAFA}^{+}$(high+low). Total insulin ${ }^{+}$cells counted: P2, 654 cells from four pancreases; P11, 1,140 cells from four pancreases; adult, 2,127 cells from five pancreases. Mean $\pm \mathrm{SEM} ;{ }^{*} p<0.05$ with respect to previous age 
Fig. 4 Proteins of selected genes have similar agedependent increases as mRNA. Insulin (a), GLP1R (b) and PCSK1 (c) had very low levels of immunostaining at $\mathrm{P} 2$, increasing until adult. To allow comparison of protein levels at different ages paraffin sections were immunostained in parallel and photographed in confocal mode at same settings. Ad, adult
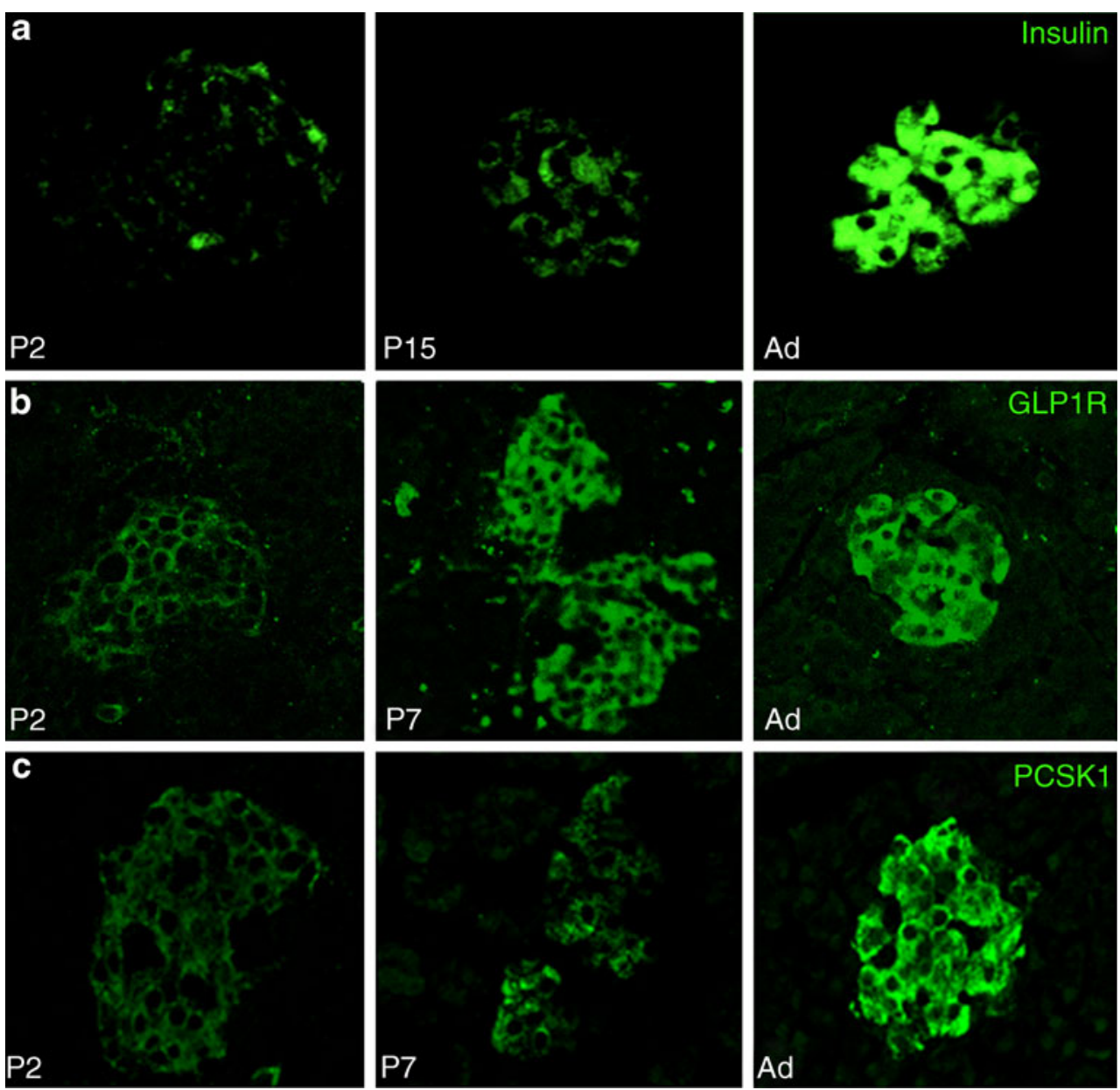

which was maintained up to P28. Most other genes were unchanged over the neonatal period, e.g. catalase, a scavenger enzyme that has low levels in adult islets (ESM Fig. 1). The findings that $P d x l$ expression reached adult levels already by P7 whereas Mafa expression remained significantly lower than adult even through P21 suggest Mafa as the factor that drives final maturation of beta cell function and enhances glucose-stimulated insulin secretion.

Adenoviral overexpression of $P d x 1$ and MAFA in $P 2$ islets To determine the effect of Pdxl and Mafa on the maturation of the neonatal beta cells more directly, we overexpressed each separately using adenoviruses in P2 islets and assessed expression of putative target genes, nuclear localisation of the transcription factor and glucoseresponsive insulin secretion.

$P d x 1$ overexpression achieved a 2.4 -fold increase in mRNA (Fig. 5a), with significant increases in Mafa, Neurodl and Gck mRNA, but no change in Nkx6-1, cMaf (also known as Maf), Mafb, Glp1r, Glut2 (also known as Slc2a2), Ins2, preproinsulin or pyruvate carboxylase mRNA. Insulin secretion was significantly increased at both 2.8 and $16.8 \mathrm{mmol} / \mathrm{l}$ glucose (Fig. 6a) in Ad-Pdxl- infected cells compared with Ad-Gfp controls. However, there was no increase in fold change because the responses to low and high glucose did not differ (Fig. 6b). This lack of glucose responsiveness was seen even though insulin content significantly increased after $P d x l$ overexpression (Fig. 6c).

MAFA overexpression was adjusted to obtain a modest $50 \%$ increase of Mafa levels at $72 \mathrm{~h}$ compared with control Ad-Gfp-infected cells; this is comparable to the level seen in P9-P28 islets. This change was due to increased exogenous MAFA as the amount of PCR product for $3^{\prime}$ UTR message (endogenous gene, see Methods) was unchanged (Fig. 5b). With this overexpression, transcription of Neurod1, Nkx6-1 and Gck were significantly upregulated, as was Glp1r. However, Ins2, Pdx1, Glut2, various metabolic genes and channels were not significantly changed. There was no change in $M a f b$, whereas $c-M a f$ was significantly reduced.

In addition to the enhanced expression of several key genes, MAFA overexpression in $\mathrm{P} 2$ cells increased nuclear levels of MAFA. As with the islets within the pancreas (Fig. 3), Ad-Gfp islet cells after $72 \mathrm{~h}$ infection had low nuclear MAFA protein: $51 \%$ of these cells had no 
a

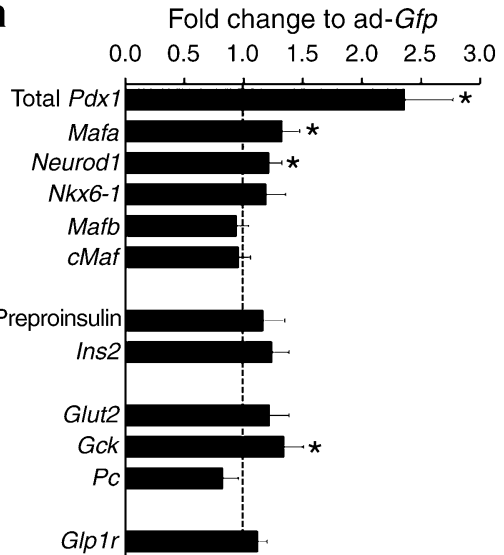

Fig. 5 Effect of adenoviral-mediated increase of $P d x 1$ and Mafa on genes important for beta cell function. After $72 \mathrm{~h}$ culture adenoviralmediated overexpression of $P d x 1$ (a) or MAFA (b) P2 islets had significant increases of total Mafa mRNA (hMAFA; see Methods) and total $P d x l$ mRNA. Overexpression of $P d x l$ upregulated Mafa,

detectable nuclear MAFA. However, Ad-MAFA cells were 91\% MAFA-positive with 38\% MAFA $^{\text {high }}$ and $53 \%$ MAFA $^{\text {low }}$ nuclear staining (ESM Fig. 5a). As the human $M A F A$ vector included an Herpes simplex virus (HSV) tag, we confirmed that the adenoviral-expressed human MAFA in infected cells was preferentially localised in the nucleus (ESM Fig. 5b).

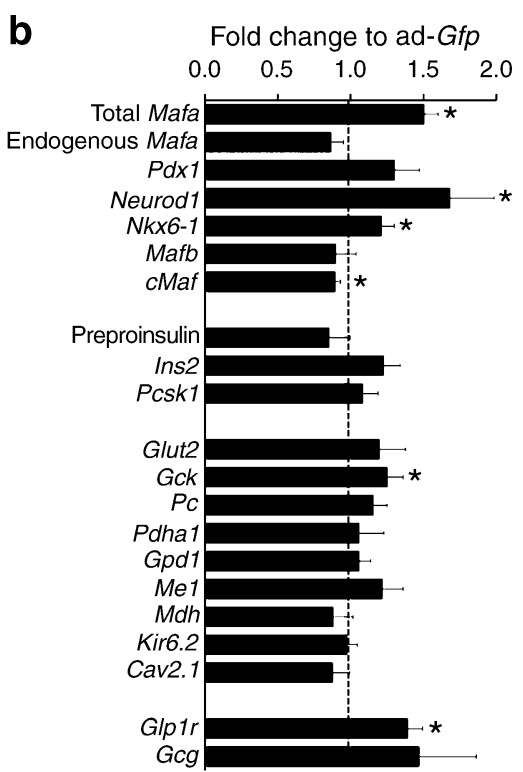

Neurod1 and Gck whereas overexpression of Mafa had upregulated Neurod1, Nkx6-1, Gck and Glp1r. Quantitative RT-PCR; expression compared with Ad-Gfp infected cells (equal to 1, dotted line). Mean \pm SEM, $n=4-6$ independent experiments; ${ }^{*} p<0.05$

Importantly, MAFA overexpression induced glucosestimulated insulin secretion. In static incubations Ad$M A F A$-infected cells significantly decreased basal insulin secretion at $2.8 \mathrm{mmol} / 1$ glucose while significantly increasing insulin secretion in $16.8 \mathrm{mmol} / \mathrm{l}$ glucose compared with Ad-Gfp cells (Fig. 6a). Insulin secretion increased fourfold from low to high glucose (Fig. 6b), a change comparable to
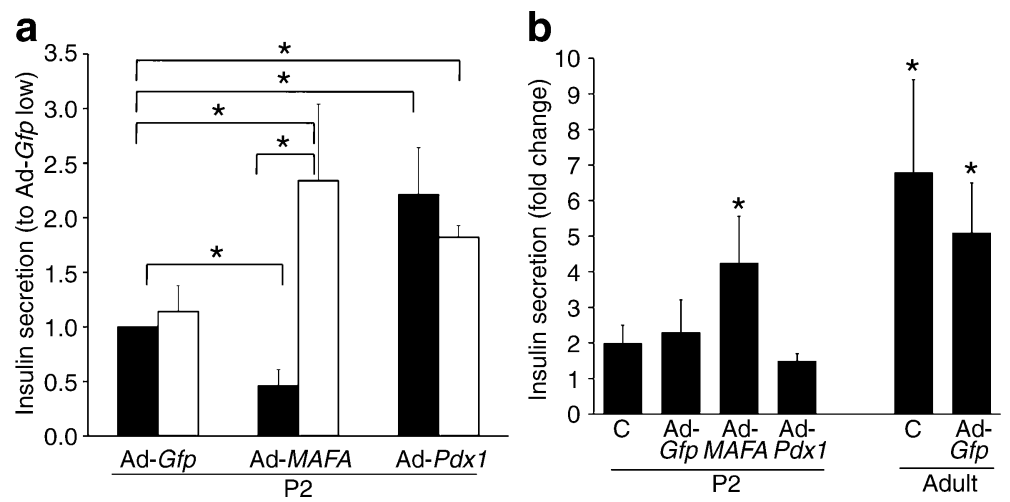

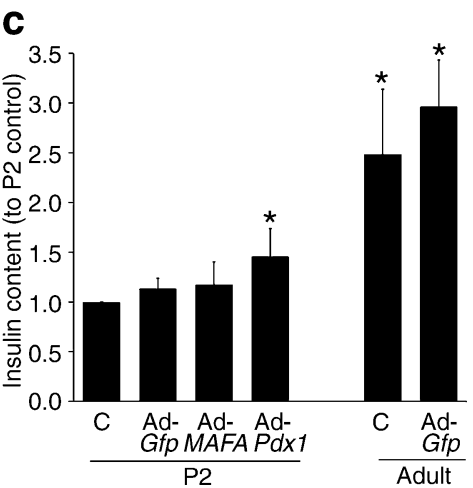

Fig. 6 Insulin secretion in static incubation and insulin content after Ad- $P d x l$, Ad-MAFA and Ad-Gfp infection. a Insulin secretion in response to $16.8 \mathrm{mmol} / \mathrm{l}$ (white bar) glucose increased in both Ad- $P d x 1$ and Ad-MAFA infected P2 cells compared with Ad-Gfp infected cells after 5 days culture. However, insulin secretion in $2.6 \mathrm{mmol} / 1$ (black bar) glucose from Ad-MAFA infected cells significantly decreased while that from Ad- $P d x l$ increased almost as much as with high glucose. ${ }^{*} p<0.05$ in marked comparisons. b Insulin secretion expressed as fold change in response to glucose stimulation reflects the glucose responsiveness of the cultured cells. As previously shown, neonatal (P2) islets have little glucose responsiveness when compared with adult islets similarly cultured (Ad-GfpP2: $7 \pm 2 \mathrm{pg}$ insulin/ng DNA at $2.8 \mathrm{mmol} / 1$ and $9 \pm 2$ at $16.8 \mathrm{mmol} / \mathrm{l}$; Ad- $G f p$ adult: $11 \pm 2 \mathrm{pg}$ insulin/ng DNA at $2.8 \mathrm{mmol} / \mathrm{l}$ and $47 \pm 13$ at $16.8 \mathrm{mmol} / \mathrm{l}$ ). Only Ad-MAFA increased the glucose responsiveness of the P2 cells; the uninfected, Ad- $G f p$ and Ad- $P d x l$ infected cells had little to no response to the increased glucose concentration. ${ }^{*} p<0.05$ compared with untreated cultured P2 cells (c). $\mathbf{c}$ There was no change in insulin content (pg/ng DNA) in Ad-MAFA infected P2 islets and cultured control islets (untreated or Ad-Gfp infected), but insulin content was significantly higher in Ad- $P d x 1$ compared with cultured uninfected (c) cells. Mean $\pm \mathrm{SEM} ; n=4$ independent experiments in duplicate. $* p<0.05$ compared with untreated (c) cultured P2 cells 
the fivefold increase of cultured Ad-Gfp-infected adult cells. It is striking that adult glucose responsiveness was nearly achieved in MAFA-infected P2 cells that still had lower insulin expression (Figs 1b, 5b) and content (Fig. 6c) than adult cells treated and cultured under the same conditions. Considering that only about $50 \%$ of the cells were infected, the glucose responsiveness may be underestimated in these experiments. It is important to note that these Ad-infected P2 isolated islets were cultured for 5 days and thus cannot be compared with freshly isolated P2 islets.

Using the more informative RHPA to explore in more detail the improved glucose-stimulated insulin secretion in $M A F A$-overexpressing cells, we found both increased proportion of glucose-responsive cells and greater amount of insulin secreted in response to high glucose. As previously shown [26], RHPA allows the evaluation of secretion from single beta cells by detection of haemolytic plaques, whose area is proportional to the amount of insulin secreted by that individual cell (ESM Fig. 6). Confirming the previously reported lack of glucose responsiveness in neonatal rodent islets [3-5], uninfected and Ad-Gfpinfected cultured P2 controls had little response to stimulatory glucose concentrations (Fig. 7a). By contrast, robust insulin secretion was observed in uninfected and AdGfp-infected cultured adult cells, which had 7.8- and 5.4fold greater insulin secretion index at $16.8 \mathrm{mmol} / \mathrm{l}$ glucose than at $2.8 \mathrm{mmol} / \mathrm{l}$. The secretion index of Ad-MAFA P2 cells was 4.7 -fold greater at $16.8 \mathrm{mmol} / 1$ glucose than at $2.8 \mathrm{mmol} / \mathrm{l}$ (Fig. 7a), approaching that of adult cells.

The effects of Ad-MAFA on insulin secretion by neonatal islets were due partly to inducing responsiveness as seen by the significantly increased percentage of secreting cells at $16.8 \mathrm{mmol} / 1$ glucose (Fig. 7b): 30\% for uninfected, $24 \%$ for Ad-Gfp-infected cells but $55 \%$ for Ad-MAFA infected. This proportion of responding cells approached that of adults
( $69 \%$ for uninfected and $72 \%$ for Ad-Gfp). In addition, the overexpression of MAFA changed the functional subpopulations of beta cells (Fig. 7c). Adult beta cells can be grouped on their secretory capacity into three functional subpopulations by plaque areas: small, medium and large plaque-forming cells (ESM Fig. 6). In control Ad-Gfp cultured cells, the majority of cells were small plaqueforming with few of the other subpopulations. However, in Ad-MAFA beta cells the proportion of small plaque-forming cells decreased as the other two populations increased, rendering the secretory characteristics of these infected cells similar to that of adult both in number and size of secretion plaques. Thus, increased expression of Mafa in glucoseunresponsive cultured islet cells induced a functional change in these cells such that they had near-adult glucose-induced insulin secretion, a sign of maturation.

\section{Discussion}

Beta cells at birth are functionally immature, lacking the ability to respond to a changing glucose concentration, only acquiring glucose responsiveness over the first 3-4 weeks after birth [5, 25]. Here, we tested two of the three suggested transcription factors essential for beta cell specificity and insulin gene expression. We demonstrated a close relationship between the expression patterns of Mafa and some of its putative targets, including insulin, during this neonatal period. As Mafa expression from P2 through P7 was less than $10 \%$ of adult, reconstitution of Mafa at P2 provides a means to unequivocally evaluate effects of Mafa on beta cell functional development.

In such reconstitution experiments, overexpressing MAFA in neonatal cells led to their acquisition of an insulin-secretory profile similar to adult beta cells, with a

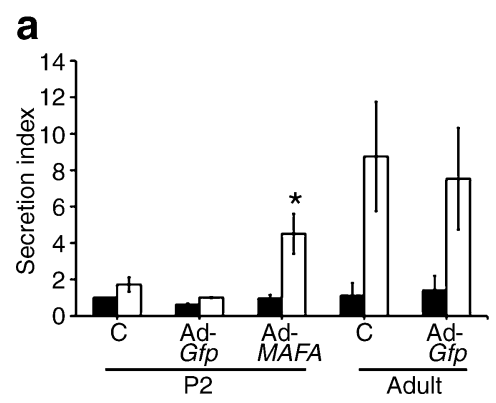

Fig. 7 Mafa expression increases percentage of secreting cells and insulin secreted per beta cell as measured by reverse haemolytic plaque assay. a After Ad-MAFA infection, cultured P2 cells have increased insulin secretion index in response to glucose stimulation; $2.6 \mathrm{mmol} / 1$ (black bar), $16.8 \mathrm{mmol} / 1$ (white bar). Mean $\pm \mathrm{SEM} ; n=3$ independent experiments. ${ }^{*} p<0.03$ respect to Ad-Gfp P2. Total number of plaques counted per condition: P2 untreated (c), 223; AdGfp P2, 595; Ad-MAFA P2, 463; untreated (c) cultured adult, 188;
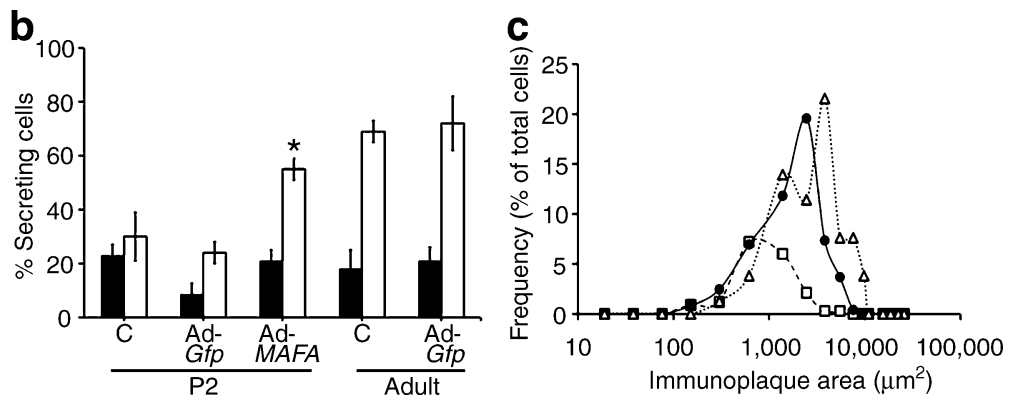

cultured adult Ad-Gfp, 256. b The percentage of insulin-secreting beta cells increased after Ad-MAFA infection. ${ }^{*} p<0.005$ respect to Ad-Gfp P2; $2.6 \mathrm{mmol} / \mathrm{l}$ (black bar), $16.8 \mathrm{mmol} / 1$ (white bar). c In response to stimulatory $16.8 \mathrm{mmol} / \mathrm{l}$ glucose, more Ad-MAFA cells are secreting and with greater individual secretion, as seen in this plot of the subpopulations from a representative experiment. P2 Adv-Gfp (white square), P2 Adv-MAFA (black circle), adult control (white triangle) 
higher percentage of secreting cells as well as greater insulin secretion in response to high glucose concentrations. Thus, increased Mafa expression may represent a mechanism responsible for enhancing the beta cell functional maturity. By contrast, $P d x 1$ reached adult levels by $\mathrm{P} 7$ and had a postnatal expression pattern that differed from the tested beta cell genes including insulin, Glut2 and Gck. Importantly, $P d x 1$ reconstitution in P2 beta cells failed to increase glucose responsiveness within the experimental timeframe. However, $P d x l$ overexpression upregulated Mafa mRNA expression, increased insulin content and increased insulin secretion in both low and high glucose concentrations.

The expression patterns of Mafa and Pdxl during the neonatal period were distinct even though both have been implicated in regulating expression of the other [13, 27, 28]. The parallel expression of insulin and Mafa, the upregulation of Mafa expression by Ad-Pdxl, and our previous observation that $\mathrm{PDX} 1^{\text {high }}$ is expressed before MAFA in insulin ${ }^{+}$cells during development [11] are consistent with $P d x 1$ being an upstream regulator of $M a f a$. Even though the induction of glucose responsiveness was not achieved by $P d x l$ overexpression within the timeframe of our experiments, we expect that with longer incubation $P d x 1$-infected P2 cells would acquire glucose responsiveness.

Mafb is also implicated in regulating Mafa expression [29], yet our results suggest the lack of such regulation in postnatal beta cells. Mafb expression had a similar pattern to $P d x 1$ and Neurodl between P7 and P15, a period when the proportion of glucagon-expressing alpha cells does not increase [30]. Two likely contributors to enhanced Mafb expression are induction of $M a f b$ in maturing glucagon ${ }^{+}$ cells and transient production of MAFB [11] in beta cells formed after birth [31, 32]. In the mouse around P14 only a few insulin ${ }^{+}$cells are still MAFB ${ }^{+}[11,33]$. The dramatic reduction in expression of $P d x 1$, Neurodl and Mafb about P15 was not accompanied by reduced Mafa expression and so suggests additional factors may regulate Mafa expression during this time.

A previous report [13] had suggested Gck, Pcskl and Glplr as putative Mafa targets. As Mafa knockout mice did not show any embryonic phenotype, it was not surprising that a recently published paper [33] failed to detect these genes as being directly under the control of either Mafa or $M a f b$ in E18.5 Mafb $b^{\text {null }}$ or $M a f a^{\text {DPanc }} M a f b^{\text {null }}$ mice. However, our data of parallel expression of Glp1r, insulin, Glut2 and Pcskl with Mafa support their being Mafa targets postnatally. Gck expression was upregulated by both $P d x l$ and Mafa overexpression, yet the time course of its expression differed significantly from both. In addition to Mafa and $P d x l$, physiological stimuli, such as thyroid hormones [34], may regulate Gck expression.
In our previous report showing developing insulin ${ }^{+}$ cells switching from $\mathrm{MAFB}^{+} \mathrm{MAFA}^{-} \mathrm{INS}^{+}$to $\mathrm{MAFB}^{-}$ MAFA $^{+} \mathrm{INS}^{+}$cells [11], we suggested that Mafa may be important for the postnatal functional maturation of beta cells. Our current results strongly indicate such a role. While global Mafa-knockout mice showed embryonic Mafa expression was not essential for islet architecture at birth, that study did not address its function in maturation of beta cells [19]. A modest increase in fasting glucose at 4 weeks was the earliest defect reported in the Mafa knockout mice, and this was followed by impaired glucose-stimulated insulin secretion at 8 weeks. There was no analysis of whether this impairment was due to a lack of maturation, an intrinsic defect or glucotoxicity. Neonatal rodent beta cells are analogous to a loss-of-function model owing to their very low Mafa expression at birth, and we suggest that the acquisition with mature beta cell function after reconstitution of Mafa expression to levels comparable with adult beta cells essentially represents a functional rescue. Demonstration of physiological signals regulating Mafa expression during the neonatal period will underscore its importance as an essential transcription factor for functional maturation of beta cells.

In the early neonatal period in rodents (Fig. 3, ESM Fig. 2) MAFA protein not only has a very low expression but has mainly cytoplasmic localisation; with time it gains nuclear localisation. The relative proportion of nuclear and cytoplasmic MAFA differs somewhat between rats and mice during this period, but the presence of some cytoplasmic MAFA across species suggests that such translocation is a normal feature of neonatal development. Although the mechanisms controlling MAFA localisation in beta cells during the postnatal period are unknown and beyond the scope of this work, cytoplasmic localisation of transcription factors has been described $[35,36]$. Recently a nucleo-cytoplasmic translocation of MAFA was described as a result of oxidative stress in the adult beta cell [37].

Maternal hyperglycaemia leads to precocious maturation and hyperplasia of fetal beta cells [4, 38], and chronic in vitro exposure of fetal beta cells to elevated glucose levels induced maturation of glucose-stimulated insulin secretion [4]. Both $M a f a$ and $P d x l$ are glucose-responsive transcription factors and so could have enhanced expression. However, increased expression of Mafa, but not $P d x l$, converted immature neonatal beta cells into glucoseresponsive cells within the timeframe studied, supporting the more direct role of Mafa in the maturation process.

Although much emphasis has been put on elucidating the transcription factors involved in the embryonic differentiation of beta cells (reviewed by Jensen [39]), identification of factors that drive functional maturation in the postnatal period is essential to harvest the true potential of human embryonic stem (hES) cells. Currently, differentiat- 
ed insulin-positive cells derived in vitro lack glucosestimulated insulin secretion and still express MAFB $[1,20]$. Only several months after transplantation, these hES cellderived insulin ${ }^{+}$cells were shown to be glucose responsive and to express MAFA [2]. Conversely, the loss of Mafa mRNA and protein expression occur in dysfunctional beta cells from rats 4 weeks after $90 \%$ pancreatectomy and from 12-week-old hyperglycaemic $d b / d b$ mice [40]. Thus, identification of the neonatal physiological stimuli that regulate Mafa and $P d x l$ expression will be important for developing in vitro strategies to convert stem-cell derived insulin-expressing cells into mature, fully functional beta cells for cell-based therapies for diabetes.

Acknowledgements The authors thank J. Lock, T. Salameh and C. Cahill, all of the Joslin Diabetes Center, for their expert technical assistance. This study was supported by NIH R01 DK 66056 (S. Bonner-Weir), R01 DK 60127 (A. Sharma), P30 DK36836 Joslin Diabetes and Endocrinology Research Center (DERC) Advanced Microscopy Core grants as well as the Juvenile Diabetes Research Foundation, Diabetes Research and Wellness Foundation, the Graetz Fund and an important group of private donors. I. El Khattabi was supported by Joslin T32 DK007260, W. C. Li by a JDRF Post doctoral fellowship, A. Koh by a Singapore National Medical Research Council Research fellowship grant, and K. Juhl by a Lundbeckfonden fellowship.

Duality of interest The authors declare that there is no duality of interest associated with this manuscript.

\section{References}

1. D'Amour KA, Bang AG, Eliazer S et al (2006) Production of pancreatic hormone-expressing endocrine cells from human embryonic stem cells. Nat Biotechnol 24:1392-1401

2. Kroon E, Martinson LA, Kadoya K et al (2008) Pancreatic endoderm derived from human embryonic stem cells generates glucose-responsive insulin-secreting cells in vivo. Nat Biotechnol 26:443-452

3. Freinkel N, Lewis NJ, Johnson R, Swenne I, Bone A, Hellerstrom C (1984) Differential effects of age vs glycemic stimulation on the maturation of insulin stimulus-secretion coupling during culture of fetal rat islets. Diabetes 33:1028-1038

4. Hellerstrom C, Swenne I (1991) Functional maturation and proliferation of fetal pancreatic beta-cells. Diabetes 40(Suppl 2):89-93

5. Bliss CR, Sharp GW (1992) Glucose-induced insulin release in islets of young rats: time-dependent potentiation and effects of 2bromostearate. Am J Physiol 263:E890-E896

6. Navarro-Tableros V, Fiordelisio T, Hernandez-Cruz A, Hiriart M (2007) Physiological development of insulin secretion, calcium channels, and GLUT2 expression of pancreatic rat beta-cells. Am J Physiol Endocrinol Metab 292:E1018-E1029

7. Rorsman P, Arkhammar P, Bokvist K et al (1989) Failure of glucose to elicit a normal secretory response in fetal pancreatic beta cells results from glucose insensitivity of the ATP-regulated K+ channels. Proc Natl Acad Sci U S A 86:4505-4509

8. Bliss CR, Sharp GW (1994) A critical period in the development of the insulin secretory response to glucose in fetal rat pancreas. Life Sci 55:423-427
9. Tan C, Tuch BE, Tu J, Brown SA (2002) Role of NADH shuttles in glucose-induced insulin secretion from fetal beta-cells. Diabetes 51:2989-2996

10. Jermendy A, Toschi E, Aye T et al (2010) Rat neonatal beta cells lack the specialised metabolic phenotype of mature beta cells. Diabetologia doi:10.1007/s00125-010-2036-x

11. Nishimura W, Kondo T, Salameh T et al (2006) A switch from MafB to MafA expression accompanies differentiation to pancreatic beta-cells. Dev Biol 293:526-539

12. Keller DM, McWeeney S, Arsenlis A et al (2007) Characterization of pancreatic transcription factor $\mathrm{Pdx}-1$ binding sites using promoter microarray and serial analysis of chromatin occupancy. J Biol Chem 282:32084-32092

13. Wang H, Brun T, Kataoka K, Sharma AJ, Wollheim CB (2007) MAFA controls genes implicated in insulin biosynthesis and secretion. Diabetologia 50:348-358

14. Offield MF, Jetton TL, Labosky PA et al (1996) PDX-1 is required for pancreatic outgrowth and differentiation of the rostral duodenum. Development 122:983-995

15. Jonsson J, Carlsson L, Edlund T, Edlund H (1994) Insulinpromoter-factor 1 is required for pancreas development in mice. Nature 371:606-609

16. Sharma A, Stein R (1994) Glucose-induced transcription of the insulin gene is mediated by factors required for beta-cell-typespecific expression. Mol Cell Biol 14:871-879

17. Waeber G, Thompson N, Nicod P, Bonny C (1996) Transcriptional activation of the GLUT2 gene by the IPF-1/STF-1/IDX-1 homeobox factor. Mol Endocrinol 10:1327-1334

18. Ahlgren U, Jonsson J, Jonsson L, Simu K, Edlund H (1998) betacell-specific inactivation of the mouse Ipf1/Pdx1 gene results in loss of the beta-cell phenotype and maturity onset diabetes. Genes Dev 12:1763-1768

19. Zhang C, Moriguchi T, Kajihara M et al (2005) MafA is a key regulator of glucose-stimulated insulin secretion. Mol Cell Biol 25:4969-4976

20. Jiang J, Au M, Lu K et al (2007) Generation of insulin-producing islet-like clusters from human embryonic stem cells. Stem Cells 25:1940-1953

21. Gotoh M, Maki T, Satomi S et al (1987) Reproducible high yield of rat islets by stationary in vitro digestion following pancreatic ductal or portal venous collagenase injection. Transplantation 43:725-730

22. Zhou Q, Brown J, Kanarek A, Rajagopal J, Melton DA (2008) In vivo reprogramming of adult pancreatic exocrine cells to betacells. Nature 455:627-632

23. Heller RS, Kieffer TJ, Habener JF (1997) Insulinotropic glucagonlike peptide I receptor expression in glucagon-producing alphacells of the rat endocrine pancreas. Diabetes 46:785-791

24. Schuppin GT, Bonner-Weir S, Montana E, Kaiser N, Weir GC (1993) Replication of adult pancreatic-beta cells cultured on bovine corneal endothelial cell extracellular matrix. In Vitro Cell Dev Biol Anim 29A:339-344

25. Aguayo-Mazzucato C, Sanchez-Soto C, Godinez-Puig V, Gutierrez-Ospina G, Hiriart M (2006) Restructuring of pancreatic islets and insulin secretion in a postnatal critical window. PLoS ONE 1:e35

26. Salomon D, Meda P (1986) Heterogeneity and contact-dependent regulation of hormone secretion by individual B cells. Exp Cell Res 162:507-520

27. Samaras SE, Zhao L, Means A, Henderson E, Matsuoka TA, Stein $\mathrm{R}$ (2003) The islet beta cell-enriched RIPE3b1/Maf transcription factor regulates pdx-1 expression. J Biol Chem 278:12263-12270

28. Raum JC, Gerrish K, Artner I et al (2006) FoxA2, Nkx2.2, and PDX1 regulate islet beta-cell-specific mafA expression through conserved sequences located between base pairs -8118 and -7750 upstream from the transcription start site. Mol Cell Biol 26:5735-5743 
29. Artner I, Blanchi B, Raum JC et al (2007) MafB is required for islet beta cell maturation. Proc Natl Acad Sci U S A 104:3853-3858

30. Scaglia L, Cahill CJ, Finegood DT, Bonner-Weir S (1997) Apoptosis participates in the remodeling of the endocrine pancreas in the neonatal rat. Endocrinology 138:1736-1741

31. Bonner-Weir S, Toschi E, Inada A et al (2004) The pancreatic ductal epithelium serves as a potential pool of progenitor cells. Pediatr Diabetes 5(Suppl 2):16-22

32. Chintinne M, Stange G, Denys B et al (2010) Contribution of postnatally formed small beta cell aggregates to functional beta cell mass in adult rat pancreas. Diabetologia 53:2380-2388

33. Artner I, Hang Y, Mazur M et al (2010) MafA and MafB regulate genes critical to $\beta$ cells in a unique temporal manner. Diabetes 59:2530-2539

34. Partridge NC, Hoh CH, Weaver PK, Oliver IT (1975) Premature induction of glucokinase in the neonatal rat by thyroid hormone. Eur J Biochem 51:49-54
35. Matsumoto M, Accili D (2005) All roads lead to FoxO. Cell Metab 1:215-216

36. Kishi A, Nakamura T, Nishio Y, Maegawa H, Kashiwagi A (2003) Sumoylation of Pdx1 is associated with its nuclear localization and insulin gene activation. Am J Physiol Endocrinol Metab 284: E830-E840

37. Harmon JS, Bogdani M, Parazzoli SD et al (2009) Beta-cellspecific overexpression of glutathione peroxidase preserves intranuclear MafA and reverses diabetes in $\mathrm{db} / \mathrm{db}$ mice. Endocrinology 150:4855-4862

38. Aerts L, van Assche FA (1977) Rat foetal endocrine pancreas in experimental diabetes. J Endocrinol 73:339-346

39. Jensen J (2004) Gene regulatory factors in pancreatic development. Dev Dyn 229:176-200

40. Kondo T, El Khattabi I, Nishimura W et al (2009) p38 MAPK is a major regulator of MafA protein stability under oxidative stress. Mol Endocrinol 23:1281-1290 